\title{
GREEN-SYNTHESIZED GOLD NANOPARTICLES SUPPORTED ON CELLULOSE NANOWHISKERS FOR EASY-TO-INTERPRET COLORIMETRIC DETECTION OF CADMIUM (II)
}

\author{
FERNANDA L. MIGLIORINI, KELCILENE B. R. TEODORO ${ }^{* * *}$ and \\ DANIEL S. CORREA ${ }^{* * * *}$ \\ *Nanotechnology National Laboratory for Agriculture (LNNA), Embrapa Instrumentação, \\ 13560-970, São Carlos, SP, Brazil \\ ${ }^{* *} P P G Q$, Department of Chemistry, Center for Exact Sciences and Technology, Federal University of São \\ Carlos (UFSCar), 13565-905, São Carlos, SP, Brazil \\ $\square$ Corresponding authors: F. L. Migliorini, fernandamigliorini@yahoo.com.br \\ D.S.Correa, daniel.correa@embrapa.br
}

Received August 29, 2019

In the present study, we report on a simple and practical optical sensor based on cellulose nanowhiskers functionalized with gold nanoparticles (CNW/AuNP), which was applied as a colorimetric sensor for detecting Cd (II). Our results revealed that a simple and fast synthesis was capable to produce small and well-controlled CNW/AuNP nanocomposites. These nanocomposites can bind to Cd (II), owing to the citrate anions present on the AuNP surface, and this process is followed by an optical change in the surface plasmon resonance (SPR) band of AuNPs. As a consequence, a linear decrease of absorbance was verified as the $\mathrm{Cd}$ (II) concentration increased in the range 500-2000 $\mathrm{nM}$, yielding a detection limit of $60 \mathrm{nM}$. Our sensor also proved to be suitable for real samples analyses, even in the presence of other interfering substances, indicating its potential for $\mathrm{Cd}$ (II) colorimetric sensing applications.

Keywords: cellulose nanowhiskers, gold nanoparticles, cadmium, heavy metal monitoring, optical sensor, colorimetric sensor

\section{INTRODUCTION}

Cadmium (Cd (II)) is considered one of the most toxic metals, it is non-biodegradable and has a long half-life in the biosphere. ${ }^{1}$ The sources of cadmium pollution arise from non-ferrous metal manufacturing, and effluents released from electroplating and fertilizers. ${ }^{2}$ This metal can be extremely harmful to human health, causing, for instance, diabetes, lung cancers, hypertension, osteoporosis, among other diseases, and, therefore, its detection and monitoring are of great importance..$^{3-5}$ Although some methods have been employed for the detection of heavy metals, including electrochemical measurements, fluorescent chemosensors, surface plasmon resonance (SPR) and colorimetric sensors, easyto-interpret and expedite analytical methods to detect Cadmium in real water samples are still scarce and pose a great challenge to overcome, which was the main task of this work..$^{6-9}$

Colorimetric sensors present remarkable advantages compared to other analytical techniques, including high sensitivity and selectivity, low detection limit and simplicity, allowing the observation of the color change with the naked eye. ${ }^{10-11}$ Noble metal nanomaterials are of outmost importance in several fields of nanotechnology, ${ }^{12-13}$ and among them, gold nanoparticles (AuNPs) have received a lot of attention due to their excellent characteristics, such as strong optical absorption, scattering and fluorescence quenching properties, combined with exciting chemical and biological properties and low or no toxicity. ${ }^{13-17}$ AuNPs can be a potential material for cadmium colorimetric detection, due

Cellulose Chem. Technol., 54 (5-6), 407-413(2020) 
to the capability to induce aggregation of AuNPs, which causes a strong overlap between the plasmon fields of the nearby nanoparticles, resulting in visual color changes. ${ }^{18}$

Several well-established methods have been employed for AuNP synthesis, but more recently, alternative green methodologies have gained importance, ${ }^{16,19}$ once they avoid the use of toxic and harmful reactants and materials. Additionally, such syntheses allow the formation of smaller nanoparticles with a lower coalescence level. ${ }^{20-22}$ Small AuNPs are highly needed for colorimetric cadmium detection, once the mechanism involves the redshift of SPR bands as a consequence of AuNP aggregation. In this context, the use of cellulose in green synthesis is advantageous due to its non-toxicity and biodegradability, as well as to the possibility to obtain it from diverse natural sources, including crop wastes. $^{23-24}$ Polysaccharides such as cellulose present in their chemical composition a large number of hydroxyl groups, a hemicetal reducing end and other functionalities that enable their application in green synthesis of metal nanoparticles. ${ }^{21,25-27}$

In this context, here we developed an optically active nanoplatform able to work as an easy-tointerpret colorimetric sensor for $\mathrm{Cd}$ (II). The nanoplatform was based on a hybrid system composed of cellulose nanowhiskers and gold nanoparticles (CNW/AuNP), which were prepared by in situ chemical reduction using a sodium citrate solution. The reaction strategy employed here guaranteed the dispersion of small AuNPs and allowed exploring the interesting properties of the nanoplatform for colorimetric detection of $\mathrm{Cd}$ (II) in water samples. Moreover, the use of colloidal suspension excludes additional steps required to produce gels or films, which enables the hybrid system to be directly employed as a colorimetric Cd (II) sensor after completion of a fast and simple green synthesis employing cellulose.

\section{EXPERIMENTAL \\ Reagents}

White cotton was obtained from Apolo - Brazil. Sulphuric acid, sodium citrate, cadmium (II) nitrate, mercury (II) acetate, lead (II) nitrate, copper (II) nitrate, aluminum nitrate (III), chromium oxide (III), silver sulfate, iron sulphate (II) and nickel (II) nitrate were all purchased from LabSynth Chemical (Brazil). Dialysis membrane (D9402) and gold (III) chloride hydrate were purchased from Sigma-Aldrich.
Synthesis of cotton cellulose nanowhiskers (CNW)

CNW were obtained via acid hydrolysis of natural fibers, following the methodology previously described. $^{21}$ In this experiment, $5.0 \mathrm{~g}$ of commercial white cotton was added to $100 \mathrm{~mL}$ of $60.0 \mathrm{wt} \% \mathrm{H}_{2} \mathrm{SO}_{4}$ aqueous solution previously heated at $45{ }^{\circ} \mathrm{C}$. The hydrolysis was performed under constant stirring during 75 minutes, and cold water $(500 \mathrm{~mL})$ was added to the reaction medium in order to stop the reaction, which was then washed by centrifugation at 10,000 rpm for 10 minutes. Dialysis against distilled water was performed in order to neutralize the $\mathrm{CNW}$ suspension, which was then ultrasonicated during 5 minutes using $20 \%$ of amplitude and freeze-dried in a Thermo Fisher Scientific, SuperModulyo 220.

\section{CNW/AuNP synthesis}

CNW/AuNP was produced by adding $\mathrm{CNW}$ in AuNP synthesis, following the Turkevich method, ${ }^{28}$ in which gold (III) chloride hydrate was used as precursor and sodium citrate was used as reducing and stabilizing agent. The synthesis was performed in a round-bottom flask connected to a reflux system. This reaction medium was composed of $200 \mathrm{~mL}$ of gold (III) aqueous solution $\left(3.7 \times 10^{-4} \mathrm{~mol} \mathrm{~L}^{-1}\right)$ and $20 \mathrm{~mL}$ of aqueous $\mathrm{CNW}$ suspension $\left(50 \mathrm{mg} \mathrm{mL}^{-1}\right)$. Once it reached the boiling point, $4 \mathrm{~mL}$ of a sodium citrate aqueous solution $\left(2.4 \times 10^{-3} \mathrm{~mol} \mathrm{~L}^{-1}\right)$ was added to the solution. The reaction was performed during 40 minutes and stored in the fridge in a glass flask, and protected from light.

\section{CNW:Au characterization}

The morphologies of CNW and CNW:AuNP were investigated by Field Emission Scanning Electron Microscopy (FESEM), using a PHILLIPS-XL30 FEGSEM microscope. Diluted suspensions $\left(0.5 \mathrm{mg} \mathrm{mL}^{-1}\right)$ of CNW and CNW:AuNP were stained with $100 \mu \mathrm{L}$ of uranyl acetate $(1.5 \mathrm{wt} \%)$. Next, $1.5 \mu \mathrm{L}$ of each stained suspension was dripped on a hot silicon board, and left to dry in a desiccator at room temperature. The dimensions of CNW and AuNPs were estimated using Image J software, and 100 measurements were used for calculations.

The optical properties of the CNW/AuNP nanocomposite were evaluated by UV-Vis absorption spectroscopy, monitoring the typical AuNP band at $525 \mathrm{~nm}$, using a Shimadzu UV-16000 spectrometer, software UV Probe 2.31. Samples were placed in a 1 $\mathrm{cm}$ optical path quartz cell and ultrapure water (Millipore system) was used as blank for the measurements. The mean sizes of AuNPs before and after the analyte addition were evaluated (in triplicate) by Dynamic Light Scattering (DLS), using a Malvern Zetasizer Nano ZS.

\section{Cadmium detection essay}

Experiments to detect $\mathrm{Cd}$ (II) were performed directly using the CNW/AuNP aqueous suspension. $\mathrm{Cd}$ 
(II) solutions were prepared by varying the metal concentration in the range from 500 to $2000 \mathrm{nM}$. For this purpose, $1 \mathrm{~mL}$ of $\mathrm{Cd}$ (II) solution was added to 4 $\mathrm{mL}$ of $\mathrm{CNW} / \mathrm{AuNP}$ solution. The incubation time was optimized, in the range 10-60 minutes, and the band at $525 \mathrm{~nm}$ was monitored.

In order to evaluate the sensor selectivity, heavy metal interferents $\left(\mathrm{Ni}^{2+}, \mathrm{Pb}^{2+}, \mathrm{Hg}^{2+}, \mathrm{Cu}^{2+}, \mathrm{Al}^{+}, \mathrm{Cr}^{3+}\right.$, $\mathrm{Ag}^{+}$and $\mathrm{Fe}^{2+}$ ) were tested using solutions of the same concentration of $\mathrm{Cd}$ (II) solution, and the absorbance peak at $525 \mathrm{~nm}$ was monitored by UV-Vis spectroscopy. The sensor performance was also evaluated employing real samples (tap water and river water).

\section{RESULTS AND DISCUSSION CNW/AuNP characterization}

FESEM micrographies of representative regions of $\mathrm{CNW}$ and $\mathrm{CNW}$ :AuNP samples are depicted in Figure 1 (a) and (b), respectively. CNW presents typical needle-like structures, indicating the efficiency of the acid hydrolysis procedure to extract $\mathrm{CNW}$ from cotton fibers. ${ }^{29}$ The dimensions of $15 \mathrm{~nm}$ for diameter and 185 $\mathrm{nm}$ for length are typical of $\mathrm{CNW} .^{21}$ Figure 1 (b) reveals the presence of small spherical structures related to AuNPs. Histograms of size distribution of AuNP diameters are depicted in Figure 1 (c), yielding an average diameter $15 \pm 2 \mathrm{~nm}$. The synergism between AuNPs and CNW occurs due to electrostatic interactions between gold ions and the negatively charged groups (hydroxyl and sulphate) present on the CNW surface during the synthesis. The inclusion of $\mathrm{CNW}$ in Turkevich synthesis can lead to a lower coalescence level and consequently, the formation of smaller nanoparticles, once $\mathrm{CNW}$ also acts as a stabilizing agent. $^{21,30-31}$

The chemical reduction of gold ions to metallic gold in CNW/AuNPs was confirmed by the presence of a well-defined absorption band at $525 \mathrm{~nm}$, as displayed in Figure 2. This typical band is a consequence of the surface plasmon resonance (SPR) effect, which occurs due to a collective oscillation of conductive electrons from metallic gold nanostructures when interacting with electromagnetic radiation. ${ }^{32}$

Optical sensing of Cd (II) ions using CNW/AuNP nanocomposite

In order to evaluate the effect of $\mathrm{Cd}$ (II) on the CNW/AuNP nanocomposite, different concentrations of $\mathrm{Cd}$ (II) ions, varying from 500 to $2000 \mathrm{nM}$, were examined in order to determine the sensitivity of the colorimetric assay.
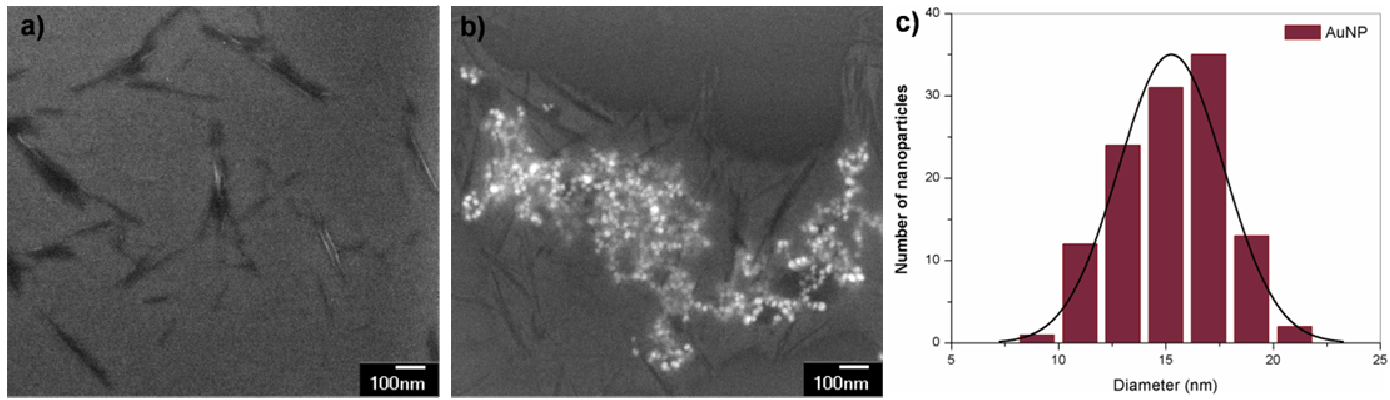

Figure 1: FESEM micrographs of CNW (a) and CNW/AuNPs (b), and histogram of AuNP size distribution (c)

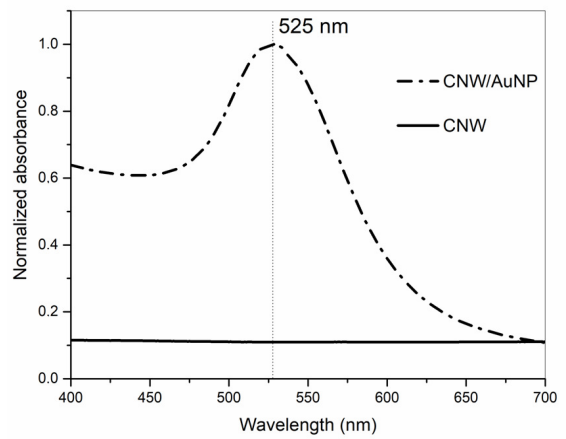

Figure 2: UV-Vis absorption spectra of CNW and CNW/AuNP 
a)

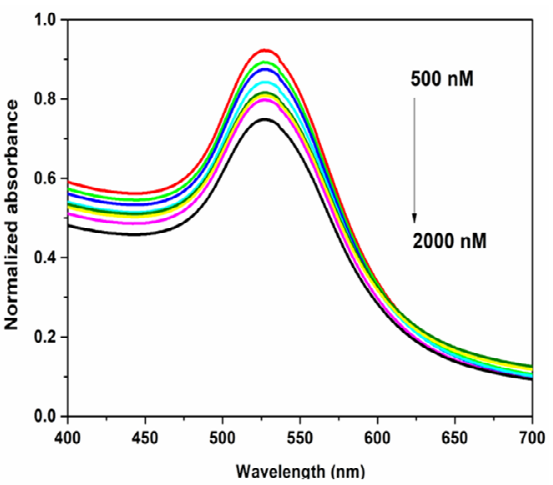

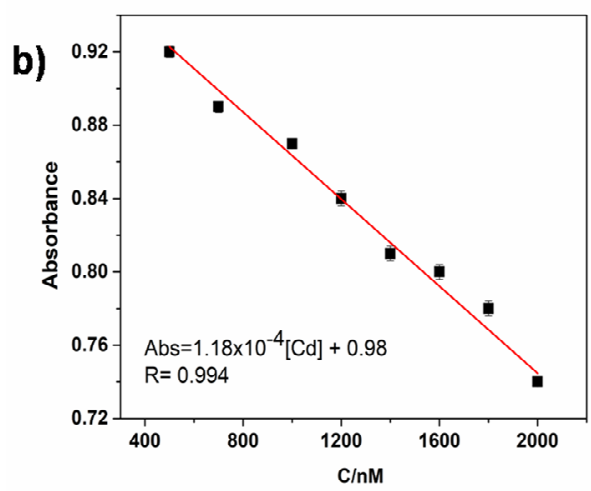

Figure 3: Optical detection of Cd (II) using CNW/AuNP nanoplatform; (a) UV-Vis absorption spectra of $\mathrm{CNW} / \mathrm{AuNPs}$ in the presence of varied concentrations of $\mathrm{Cd}$ (II), and (b) Linear response of the colorimetric assay as a function of Cd (II) concentrations

Table 1

Performance of CNW/AuNP nanocomposite in comparison with other Au NPs probes for detection of $\mathrm{Cd}$ (II) ions

\begin{tabular}{lcccc}
\hline Sensor probe & $\begin{array}{c}\text { Size } \\
(\mathrm{nm})\end{array}$ & $\begin{array}{c}\text { D.L. } \\
(\mathrm{M})\end{array}$ & $\begin{array}{c}\text { Detection } \\
\text { method }\end{array}$ & References \\
\hline Au NPs & $10-30$ & $0.07 \times 10^{-3}$ & UV-visible & 34 \\
Au NPs & 15 & $63 \times 10^{-9}$ & UV-visible & 35 \\
Au NPs & 19 & $4.6 \times 10^{-9}$ & UV-visible & 36 \\
Au NPs & 7.5 & $21 \times 10^{-9}$ & UV-visible & 1 \\
Au NPs & 15 & $60 \times 10^{-9}$ & UV-visible & This work \\
\hline
\end{tabular}

The corresponding changes in absorbance at $525 \mathrm{~nm}$, the typical band of AuNPs, were recorded using UV-Vis absorption spectroscopy (Fig. 3). In all the cases, a decrease in the absorbance at $525 \mathrm{~nm}$ was verified.

The calculation of the detection limit (D.L.) of the analyte was based on the standard deviation of the response and the slope of curve, according to D.L. $=3.3 \sigma / \mathrm{S}^{33}{ }^{33}$ in which $\sigma$ corresponds to the standard deviation of the absorbance measurement (five replicates) at $525 \mathrm{~nm}$, and $\mathrm{S}$ corresponds to the calibration curve slope (Fig. 3 (b)). Hence, the D.L. determined for Cd (II) using our colorimetric assay was $60 \mathrm{nM}$ for the concentration range of 500-2000 nM. A comparison of sensor performance regarding our proposed Cd (II) sensor and previous results available in the literature is displayed in Table 1. Our results indicate that the easily synthesized CNW/AuNP nanocomposite sensor is suitable as a nanoplatform for optical detection of Cd (II). ${ }^{1,33-}$

\section{Sensor selectivity}

The sensor selectivity for Cd (II) against common interferents was also evaluated. For this purpose, the detection of Cd (II) was evaluated in the presence of some heavy metals using solutions of the same Cd (II) concentration (1000 nM), and eventual changes in the absorbance peak at 525 $\mathrm{nm}$ were monitored using UV-Vis spectroscopy. The results displayed in Figure 4 indicate that the absorbance value at $525 \mathrm{~nm}$ for Cd (II) presents a change (increase of absorbance) of $18 \%$ when Nickel $\left(\mathrm{Ni}^{2+}\right)$ is present in the solution. On the other hand, other common heavy metals $\left(\mathrm{Pb}^{2+}\right.$, $\mathrm{Hg}^{2+}, \mathrm{Cu}^{2+}, \mathrm{Al}^{+}, \mathrm{Cr}^{3+}, \mathrm{Ag}^{+}$and $\left.\mathrm{Fe}^{2+}\right)$ had a negligible effect on the absorbance peak at 525 $\mathrm{nm}$, and consequently, did not induce remarkable solution color changes. The higher selectivity of the developed sensor towards Cd (II) relies on the fact that $\mathrm{Cd}$ (II) ions at neutral $\mathrm{pH}$ show the highest chelating ability with oxygenated functions available at citrate groups. As a consequence, the sensor becomes more selective 
to Cd (II), whereas the other metals ions here investigated show low or negligible interference in the sensor response.

\section{Analysis of Cd (II) in river and tap water}

To test the usefulness of this method, the standard addition method was used for determination of $\mathrm{Cd}$ (II) in river and tap water samples. ${ }^{37}$ River water was collected from Monjolinho River (located in São Carlos - São
Paulo, Brazil) and filtered using a paper filter ( $\mathrm{J}$ Prolab JP42). The experiments were carried out by adding different concentrations of Cd (II) ions, varying from 500 to $2000 \mathrm{nM}$, to river and tap water, and the recovery percentage was calculated as varying from $96.0 \%$ to $104.2 \%$ for river and tap water samples, respectively, as shown in Table 2. The results suggest that the developed assay is suitable for the accurate determination of $\mathrm{Cd}$ (II) in the analysis of real samples.

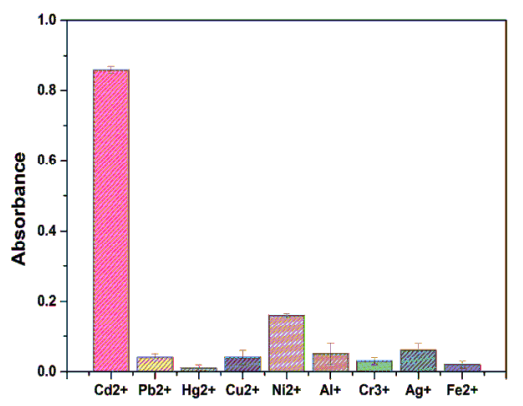

Figure 4: Selectivity of the colorimetric sensor for $\mathrm{Cd}^{2+}$ detection in the presence of common interferents

Table 2

Recovery for the determination of Cd (II) in tap water and river water samples

\begin{tabular}{lcc}
\hline Sample & \% Recovery & \% RSD \\
Cd (II) $1600 \mathrm{nM}$ & 93 & 2.1 \\
\hline River water & 90 & 1.3 \\
Tap water & \\
\hline
\end{tabular}
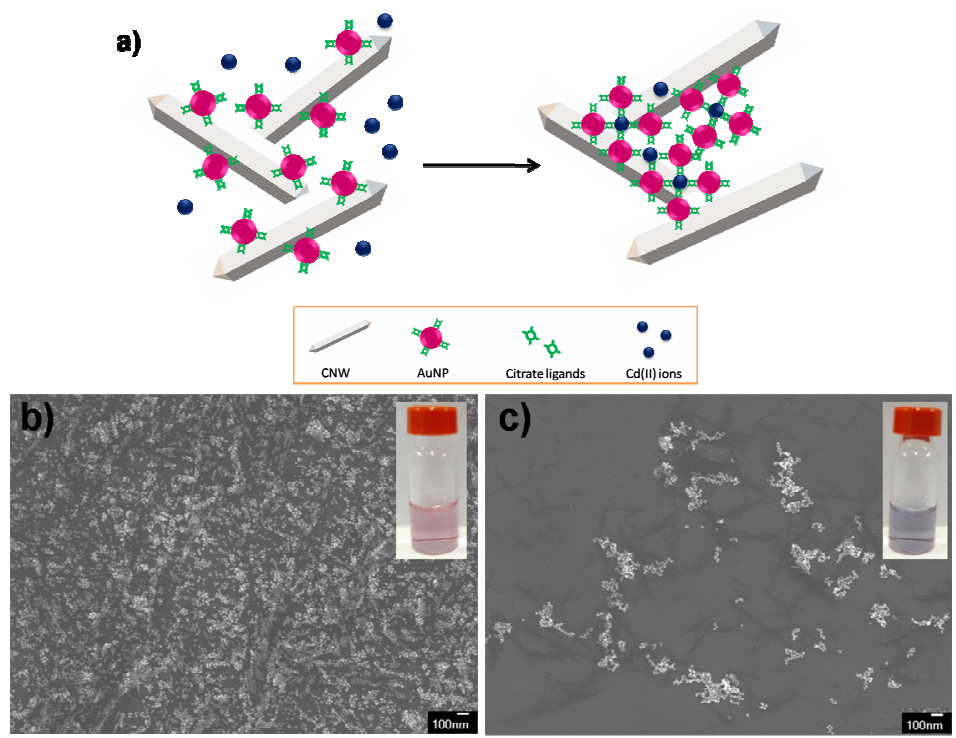

Figure 5: (a) Schematic representation of AuNP aggregation induced by the presence of Cd (II); FESEM images of $\mathrm{CNW} / \mathrm{AuNP}$ system (b) before and (c) after addition of $1 \mathrm{mM}$ of $\mathrm{Cd}$ (II) 


\section{Mechanism of Cd (II) detection}

The optical monitoring of $\mathrm{Cd}$ (II) by the CNW/AuNP nanocomposite occurs by changes in the SPR absorbance peak of AuNPs, as a consequence of metal induced particle aggregation. ${ }^{38} \mathrm{Cd}$ (II) ions coordinate with the citrate present on the AuNP surface, causing the formation of clusters of gold nanoparticles, which results in a shift of the plasmonic band to longer wavelengths, changing the color from light pink to light purple (Fig. 5 (a)). This change can be also confirmed by FESEM microscopy (Fig. 5 (bc)). Figure 5 (b) displays a great amount of welldispersed AuNPs in a CNW matrix, while Figure 5 (c) shows clusters of AuNPs formed after addition of $1 \mathrm{mM}$ de $\mathrm{Cd}$ (II). Measurements of Dynamic Light Scattering (DLS) related to particle size distribution revealed that before contact with $\mathrm{Cd}$ (II), $50.7 \%$ of particles present hydrodynamic diameter at around $35 \mathrm{~nm}$. On the other hand, after adding $1.0 \mathrm{mM}$ of Cd (II) to the CNW/AuNP suspension, the analysis revealed the presence of $91.5 \%$ of clusters with hydrodynamic diameter of $\sim 70 \mathrm{~nm}$.

\section{CONCLUSION}

A hybrid nanoplatform composed of cellulose nanowhiskers and gold nanoparticles was developed and employed as a colorimetric sensor of Cd (II) in water samples. Such a platform was obtained by a simple, affordable and green synthesis route, which resulted in AuNPs with suitable optical properties for the colorimetric detection of cadmium. The mechanism of detection was based on the cluster formation tendency of AuNPs (in the presence of Cd (II)), which caused a redshift of the AuNP SPR band. The results showed that the developed sensor for detecting Cd (II) presented a low detection limit of $60 \mathrm{nM}$ (concentration range of 500-2000 nM). Furthermore, the sensing platform showed good sensitivity and selectivity for detecting $\mathrm{Cd}$ (II) in real samples and in the presence of other interfering heavy metals. Thus, the developed sensor can be considered a potential approach for monitoring $\mathrm{Cd}$ (II) in aquatic environments with high sensitivity and selectivity. Futhermore, the method employed is simple and expedite, allowing the use of the $\mathrm{Cd}$ (II) colorimetric sensor immediately after completion of chemical synthesis.

ACKNOWLEDGEMENTS: The authors acknowledge the financial support from Fundação de Amparo à Pesquisa do Estado de São Paulo (FAPESP) (grant numbers: 2014/21184-5, 2017/12174-4, 2017/21791-7 and 2018/09414-6), Conselho Nacional de Desenvolvimento Científico e Tecnológico (CNPq), MCTI-SisNano (CNPq/402.287/2013-4), Coordenação de Aperfeiçoamento de Pessoal de Nível Superior Brasil (CAPES) and Rede Agronano (EMBRAPA) from Brazil.

\section{REFERENCES}

1 R. Yadav, P. N. Patel and V. N. Lad, Res. Chem. Intermed., 44, $2305 \quad$ (2018), https://doi.org/10.1007/s11164-017-3230-y

2 R. A. Goyer, J. Liu and M. P. Waalkes, BioMetals, 17, 555 (2004), https://doi.org/10.1023/B:BIOM.0000045738.59708.2 0

3 R. A. Bernhoft, Sci. World J., 2013, 1 (2013), https://doi.org/10.1155/2013/394652

4 S. Song, S. Zou, J. Zhu, L. Liu and H. Kuang, Food Agric. Immunol., $29, \quad 3$ (2018), https://doi.org/10.1080/09540105.2017.1354358

5 J. R. Edwards and W. C. Prozialeck, Toxicol. Appl. Pharmacol., $\quad 238, \quad 289 \quad$ (2009), https://doi.org/10.1016/j.taap.2009.03.007

6 F. L. Migliorini, R. C. Sanfelice, A. Pavinatto, J. Steffens, C. Steffens et al., Microchim. Acta, 184, 1077 (2017), https://doi.org/10.1007/s00604-017-2082-x

7 C. X. Wang, B. Wu, W. Zhou, Q. Wang, H. Yu et al., Sensor. Actuat., B Chem., 271, 225 (2018), https://doi.org/10.1016/j.snb.2018.05.079

8 A. Amirjani and D. F. Haghshenas, Sensor. Actuat., B Chem., 273, 1768 (2018), https://doi.org/10.1016/j.snb.2018.07.089

9 F. Najafzadeh, F. Ghasemi and M. R. HormoziNezhad, Sensor. Actuat., B Chem., 270, 545 (2018), https://doi.org/10.1016/j.snb.2018.05.065

10 R. Y. Robati, N. Hedayati, M. Ramezani, K. Abnous and S. M. Taghdisi, Nanomed. J., 5, 1 (2018), https://doi.org/10.22038/nmj.2018.05.001

11 I. A. A. Terra, L. A. Mercante, R. S. Andre and D. S. Correa, Biosensors, 7, $61 \quad$ (2017), https://doi.org/10.3390/bios7040061

12 L. Sutarlie, S. Y. Ow and X. Su, Biotechnol. J., 12, 1 (2017), https://doi.org/10.1002/biot.201500459

13 A. A. Borran, A. Aghanejad, A. Farajollahi, J. Barar and Y. Omidi, Radiat. Phys. Chem., 152, 137 (2018),

https://doi.org/10.1016/j.radphyschem.2018.08.010

14 M. Babaei and M. Ganjalikhani, Nanomed. J., 1, 211 (2013), https://doi.org/10.7508/nmj.2015.04.001

15 I. Fratoddi, I. Venditti, C. Cametti and M. V Russo, J. Mater. Chem. B, 2, 4204 (2014), https://doi.org/10.1039/C4TB00383G

16 A. Senthamizhan, A. Celebioglu and T. Uyar, $J$. Mater. Chem. A, 2, 12717 (2014), https://doi.org/10.1039/c4ta02295e 
17 A. H. Mohammadpour, A. Tavassoli, M. R. Khakzad, E. Zibaee, M. Afshar et al., Nanomed. J., 2, 211 (2015), https://doi.org/10.7508/NMJ.2015.03.006

18 Y. Guo, X. Liang, J. Bi, R. Ling, Y. Jiang et al., Food Chem., $285, \quad 450 \quad$ (2019), https://doi.org/10.1016/j.foodchem.2019.01.177

19 S. Govindaraju, S. R. Ankireddy, B. Viswanath and J. Kim, Sci. Rep., 1, 40298 (2017), https://doi.org/10.1038/srep40298

${ }^{20}$ H. Liu, D. Wang, Z. Song and S. Shang, Cellulose, 18, 67 (2011), https://doi.org/10.1007/s10570-0109464-0

${ }^{21}$ K. B. R. Teodoro, R. C. Sanfelice, L. H. C. Mattoso and D. S. Correa, J. Nanosci. Nanotechnol., 18, 4876 (2018), https://doi.org/10.1166/jnn.2018.15285

22 W. Yan, C. Chen, L. Wang, D. Zhang, A. J. Li et al., Carbohyd. Polym., 140, 66 (2016), https://doi.org/10.1016/j.carbpol.2015.12.049

23 A. Campos, A. R. Sena Neto, V. B. Rodrigues, V. A. Kuana, A. C. Correa et al., J. Nanosci. Nanotechnol., $\quad \mathbf{1 7}, 4970 \quad$ (2017), https://doi.org/10.1166/jnn.2017.13451

24 G. Biliuta and S. Coseri, Coord. Chem. Rev., 383, 155 (2019), https://doi.org/10.1016/j.ccr.2019.01.007

25 Y. Park, Y. N. Hong, A. Weyers, Y. S. Kim and R. J. Linhardt, IET Nanobiotechnol., 5, 69 (2011), https://doi.org/10.1049/iet-nbt.2010.0033

26 E. Morales-Narváez, H. Golmohammadi, T. Naghdi, H. Yousefi, U. Kostiv et al., ACS Nano, 9, 7296 (2015), https://doi.org/10.1021/acsnano.5b03097

27 Y. Yan, H. Yu, K. Zhang, M. Sun, Y. Zhang et al., Nano Res., $\quad 9, \quad 2088$ (2016), https://doi.org/10.1007/s12274-016-1099-5

28 J. Kimling, M. Maier, B. Okenve, V. Kotaidis, H. Ballot et al., J. Phys. Chem. B, 110, 15700 (2006), https://doi.org/10.1021/jp061667w
29 D. V. Plackett, K. Letchford, J. K. Jackson and H. M. Burt, Nord. Pulp Pap. Res. J., 29, 105 (2014), https://doi.org/10.3183/NPPRJ-2014-29-01-p105-118

30 K. Kolarova, D. Samec, O. Kvitek, A. Reznickova, S. Rimpelova et al., Jpn. J. Appl. Phys., 56, 1 (2017), https://doi.org/10.7567/JJAP.56.06GG09

31 Y. Shin, I. T. Bae, B. W. Arey and G. J. Exarhos, J. Phys. Chem. C, 112, $4844 \quad$ (2008), https://doi.org/10.1021/jp710767w

32 B. Amanulla, S. Palanisamy, S.-M. Chen, T.-W. Chiu, V. Velusamy et al., Sci. Rep., 7, 14182 (2017), https://doi.org/10.1038/s41598-017-14584-6

33 Comité de Direcção ICH, Int. Conf. Harmon. (2005),

http://www.ich.org/fileadmin/Public_Web_Site/ICH_P roducts/Guidelines/Quality/Q2_R1/Step4/Q2_R1_Gu ideline.pdf

34 N. Chen, J. Chen, J.-H. Yang, L.-Y. Bai and Y.-P. Zhang, J. Nanosci. Nanotechnol., 16, 840 (2016), https://doi.org/10.1166/jnn.2016.11618

35 V. N. Mehta, H. Basu, R. K. Singhal and S. K. Kailasa, Sensor. Actuat., B Chem., 220, 850 (2015), https://doi.org/10.1016/j.snb.2015.05.105

${ }^{36}$ Y. Wu, S. Zhan, L. Wang and P. Zhou, Analyst, 139, 1550 (2014), https://doi.org/10.1039/c3an02117c

37 S. Chaiyo, E. Mehmeti, K. Zagar, W. Siangproh and K. Kalcher, Anal. Chim. Acta, 918, 26 (2016), https://doi.org/10.1016/j.aca.2016.03.026

38 D. Vilela, M. C. González and A. Escarpa, Anal. Chim. Acta, 751, $24 \quad$ (2012), https://doi.org/10.1016/j.aca.2012.08.043 